\title{
Cognition Developing of Computer Higher Education Students Through Gamification in the Algorithm Teaching-Learning Process
}

\author{
Tiago do Carmo Nogueira ${ }^{1}$, Eudes de Souza Campos $^{2}$, Deller James Ferreira ${ }^{3}$ \\ ${ }^{1}$ Instituto Federal de Educação, Ciência e Tecnologia do Tocantins - IFTO \\ Rodovia TO 040 - Km 349 Loteamento Rio Palmeira - Lote 1 \\ Dianópolis - TO \\ ${ }^{2}$ Universidade Estadual de Goiás - UEG \\ Centro de Ensino e Aprendizagem em Rede - Cear \\ Avenida Brasil Sul, No 2.800 - Jardim Gonçalves \\ Anápolis - GO \\ ${ }^{3}$ Instituto de Informática - Universidade Federal de Goiás - UFG \\ Alameda Palmeiras, Quadra D, Câmpus Samambaia \\ Goiânia - GO \\ tiago.nogueiradifto.edu.br
}

\begin{abstract}
The scientific logical reasoning became an important skill in the students' cognitive development in algorithm teaching-learning processes, stimulating their reasoning and creativity. From this perspective, gamification has been adopted as a mediating tool in this process. Studies report that the inclusion of gamification in algorithm teaching-learning processes stimulates the students to develop new skills, making the knowledge more efficient. Therefore, this paper's purpose is to measure and understand the cognitive development and the experiences lived by students at the addition of gamification in algorithm teaching, evaluating the scientific logical knowledge acquired by them. Consequently, 44 computer higher education students were selected. They were divided into two groups: students that used the Gamification-Mediated Algorithm Teaching Method and those who participated in the traditional teaching method. To evaluate the cognitive development between these two groups, the Scientific Logical Reasoning Test was applied. The results showed that a significant number of students that used the Gamification-Mediated Algorithm Teaching Method reached the transitory intermediary and transitory scientific knowledge levels, with greater right answer rates. We also noticed that both genders gave more right answers using the gamification-mediated algorithm teaching method.
\end{abstract}

\section{Introduction}

One of the great algorithm teaching characteristics is the possibility to develop logical knowledge in the student through skills such as: reasoning, creativity, and patience [Tsai et al. 2016]. From these skills, the scientific logical reasoning plays a significant role in the students' cognitive development in the algorithm teaching-learning processes, especially in disciplines presented in the computer higher education. 
In the current formal education, scientific reasoning is a central and resulting purpose in the learning process for scientific education [Piraksa et al. 2014] [Ding et al. 2016]. With the inclusion of gamificated processes in algorithm teaching, through engaging methods, several papers report significant differences in the students' motivational aspects, which may contribute for their mental development [Seng and Yatim 2014] [Lopes et al. 2016].

New processes allow us to assist in these students' learning in algorithm disciplines and make them effective. Therefore, this research's purpose is to measure and understand the cognitive development and the experiences lived by students with the inclusion of gamification in algorithm teaching, directly measuring the scientific logical knowledge acquired by them.

Consequently, this research counted with 44 computer higher education students of the federal teaching network, in the State of Goiás. Twenty-three students participated in the algorithm introductory discipline, using the traditional teaching method, that is, based on theoretical classes and practical exercises. The remaining 21 students were submitted to the Gamification-mediated algorithm teaching method, using the Scratch tool Scratch ${ }^{1}$.

To evaluate the cognitive capacity between both sample groups, we used, as a measuring tool, Lawson's Classroom Test of Scientific Reasoning (LCTSR) ${ }^{2}$. This test consists of identification questions and variable control, of hypothetical-deductive, proportional, and probabilistic reasoning [Lawson 2004].

The results show that, in the LCTSR, most students reached a concrete scientific knowledge level, about $81 \%$; on the other hand, the transitory intermediary knowledge levels were of $13.95 \%$. We noticed that there were significant differences between the traditional teaching method and the gamification-mediated algorithm teaching method regarding the number of right answers. Consequently, the students that used the gamification-mediated algorithm teaching method reached significantly greater means.

This paper presents a theoretical referential on cognitive development and scientific reasoning (Subsection 2.1), gamification processes for algorithm teaching (Subsection 2.2), methodological procedures (Section 3), results and discussions (Section 4), and final considerations (Section 5).

\section{Cognitive Development and Gamification in Algorithm Teaching}

This section presents papers related to cognitive development, approaching features of the students' scientific reasoning (Subsection 2.1) and the gamification processes for algorithm teaching (Subsection 2.2).

\subsection{Cognitive Development and Scientific Reasoning}

Scientific reasoning became the focus of scientific education, affecting the students' academic performance, regarding the teaching-learning processes, and directly affecting their daily decision making [Ding et al. 2016] [Piraksa et al. 2014] [Jensen et al. 2017].

\footnotetext{
${ }^{1}$ Available at: https://scratch.mit.edu/

${ }^{2}$ Available at: https://www.physport.org/assessments/assessment.cfm?A=CTSR
} 
Studies that correlate the students' learning and scientific reasoning point to a greater success in context-based queries through several gain indicators in teachinglearning processes [Acar 2014]. Therefore, the scientific reasoning capability may be determined as an important factor for the students' performance, learning, and mental development promotion [Piraksa et al. 2014] [Opitz et al. 2017].

However, the cognitive development evaluation proposed by [Piaget et al. 2013], consisting in a set of specific devices through answers, with the purpose of measuring the experiences lived by the subjects, can classify the cognitive development in sensorymotor, pre-operational, concrete and formal operation [Pessoni et al. 2015]. Therefore, formal operations may be understood as a person's ability to understand more abstract concepts of the scientific reasoning.

Examining the gains of the students' scientific reasoning, it is possible to identify and classify them into three types of reasoning: concrete, formal, and post-formal. Therefore, it is possible to apply methods that identify the conceptual knowledge, comparing the performance between student groups before and after the instructions. The results may show that concrete rationalist students have a better performance in comparison with formal and post-formal rationalist students, surpassing them in a conceptual knowledge subscale [Acar and Patton 2016].

Still under this perspective, it is possible, through scientific reasoning classification, to examine the influence of the students' cognitive and motivational factors, verifying if the gender difference is a significant factor for a scientific accomplishment model. In this sense, many researchers report that the gender effects the students' understanding and their attitude towards the teaching-learning [Piraksa et al. 2014].

Studies with this purpose showed that female students surpassed male students on scientific yielding. Additionally, some results show that the most appropriate model that corresponds with this behavior includes the initial conceptual knowledge, scientific reasoning, and science value as variables that predict scientific accomplishment [Acar et al. 2015].

Therefore, through methods that enhance the scientific reasoning's capability, it is possible to identify a strong correlation between creativity technique and scientific reasoning, measuring which skills significantly contribute for the students' creativity increase in teaching-learning processes [Tsai et al. 2016].

\subsection{Gamification Processes for Algorithm Teaching}

Algorithmic thinking is fundamental for professional development, specifically to solve logical problems that are essential for cognitive development, stimulating the students' scientific reasoning in higher education.

In this sense, gamification becomes an encouraging tool to students in algorithm teaching-learning processes. For [Seng and Yatim 2014], for a while, computer games have been adopted as a part of the teaching-learning tools. Some studies show that traditional teaching methods, aligned with the inclusion of gamification, through games, stimulate students to search for new skills, with more efficient knowledge [Seng and Yatim 2014] [Lopes et al. 2016].

Therefore, pedagogic solutions and the use of serious games in teaching-learning 
processes became more inclined to encourage and engage students, efficiently allowing knowledge development [Ouahbi et al. 2015] [Topîrceanu 2017]. These solutions increase the students' interest in activities employed in the process of code revision in knowledge managing, in change managing, and in problem traceability for algorithmic proposals [Khandelwal et al. 2017] [Knutas et al. 2017].

Through the game use and student encouraging evaluation in algorithm learning with the creation of simple games, using the Scratch environment, we notice that the students' learning is encouraged, enabling them to continue their programming/algorithm studies [Ouahbi et al. 2015].

For [Khandelwal et al. 2017], while measuring gamification's impact in the algorithmic code revision processes, we notice an improvement in the codes' quality and in the students' learning. Additionally, if the industrial demand features were considered, gamificated processes may significantly increase productivity in algorithm implementations. However, simulation-mediated methods that use game concepts have significant differences in comparison with the traditional teaching methods. In this sense, students that use algorithm teaching methods, through gamification, present a better performance regarding the learning of basic concepts on algorithms in comparison with students that use the traditional teaching method [Lopes et al. 2016].

Therefore, this paper focus on the application of gamificated methods in algorithm teaching-learning processes, evaluating cognitive aspects under the perspective of higher education students' scientific reasoning knowledge, which will lead to mental and intellectual development.

\section{Methodology}

This approach evaluated the execution of an applied research, characterized by quantitative and qualitative tools to correlate algorithm traditional teaching methods and gamification-mediated methods. Therefore, in this section, we present the profile of the research's participants (Subsection 3.1), propose a gamification-mediated algorithm teaching method (Subsection 3.2), and describe Lawson's Classroom Test of Scientific Reasoning (Subsection refLawson).

\subsection{Profile of the Participants}

This paper counted with the participation of 44 computer higher education students of the federal teaching network of the State of Goiás (IFGoiano, IFG, and UFG). All were students coming from initial classes of first semester. However, none of the students had previous contact with programming and computational thinking. The workshops for application of the methods occurred for two weeks.

The students' average age was 22 years old. The group had 11 female students and 33 male students. They were divided into two groups:

- those that used the traditional teaching method (23 students);

- the participants of the gamification-mediated teaching method (21 students).

\subsection{Gamification-Mediated Algorithm Teaching Method}

Based on the method proposed by [Lopes et al. 2016], the serious game-oriented algorithm teaching method's difference is the use of gamification resources in the teaching 
processes. Therefore, Figure 1 presents a sketch of the stages employed between the traditional teaching method and the simulation-mediated teaching method (gamification).

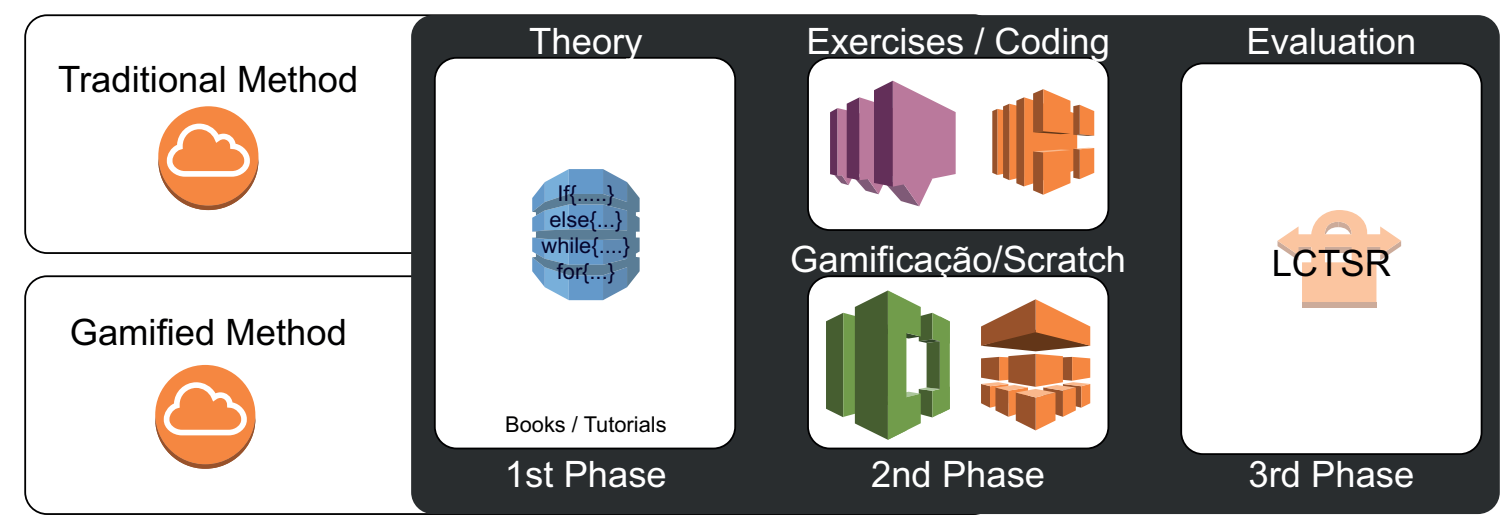

Figure 1. Stages employed in the traditional teaching and the gamificationmediated method

Figure 1 comparatively presents the stages employed between the two teaching methods measured by this research. We notice that the first stage (theory) is based in the inclusion of pedagogic tools that help the students to obtain a theoretical and referential understanding. This stage is common on both teaching methods and may be based on the concepts of the main decision and repetition commands: "if-then"; "else-then"; "if-thenelse"; "repeat-until"; "while-do", and "to-until".

In the second stage, in the traditional teaching method, the students are encouraged to perform practical exercises on algorithms, that is, to code and implement new functions, based on the concepts studies in stage 1 (theory).

In this stage, in the gamification-mediated teaching method, the students are engaged to performed practical exercises through game building, using the basic concepts studied in stage 1 (theory), presenting them to the game and gamification concepts. In this sense, the Scratch tool was used to pedagogically help in the exercises' execution in the algorithm teaching-learning process (Figure 2).

This tool uses logical blocks with items of sounds and images through interactive stories, making use of 'gamification' concepts. The most common concept can summarize gamification as the utilization of game mechanics in other contexts.For [Lopes et al. 2016], an evident feature of this tool is the ability to stimulate cooperative learning, sharing knowledge along the learning process, developing creative skills in the students to solve programming/algorithm problems.

Scratch was developed by the Lifelong Kindergarten group at the MIT Media Lab. The tool was developed in 2003 and especially designed for students between 8 and 16 years of age, but is used by people of all age groups [Resnick et al. 2009]. Scratch is used in over 150 countries, it is available in over 40 languages and it is provided free of charge for all major operating systems, Linux, Windows and Mac OS.

In the third stage, method evaluation and comparison, we proposed the application of the LCTSR. In the next section, the LCTSR's main features are presented. 


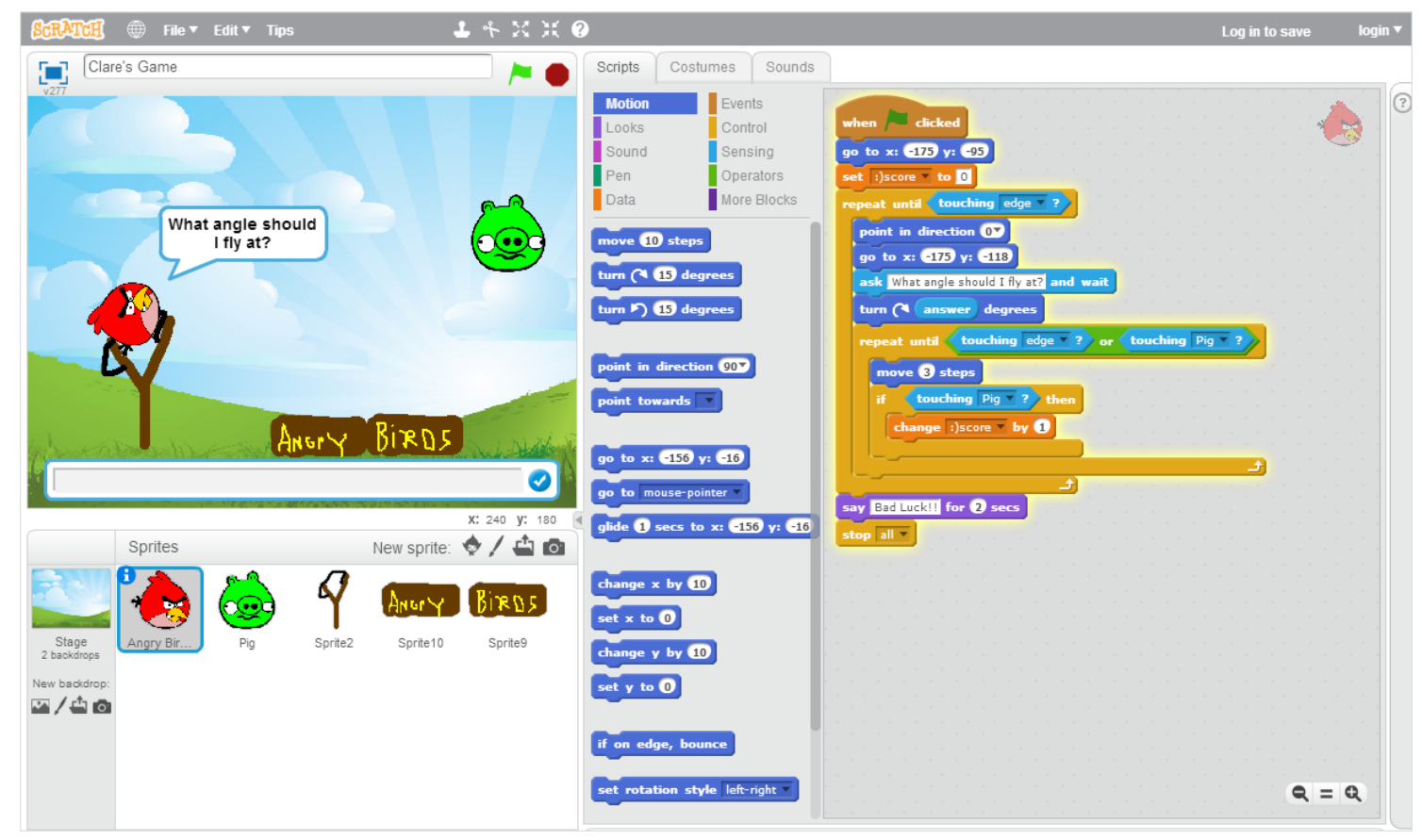

Figure 2. Scratch Simulation Tool

\subsection{Lawson's Classroom Test of Scientific Reasoning}

The first LCTSR version was proposed in 1978 and updated in 2000 [Piraksa et al. 2014] [Tsai et al. 2016]. The test has 24 questions. Each question was proposed to measure the students' scientific understanding. The questions are grouped in the following measures: mass and volume conservation - questions 1,2,3, and 4; proportional reasoning - questions 5, 6, 7, and 8; variable control - 9, 10, 11, 12, 13, and 14; probabilistic reasoning - questions 15,16, 17 and 18; correlation reasoning - questions 19 and 20; and hypothetical-deductive reason - questions 21, 22, 23, and 34 [Lawson 2000].

The LCTSR was applied in both student groups: the ones that use the traditional teaching method and the participants of the gamification-mediated algorithm teaching method. Therefore, through the test, it was possible to classify the students by scientific reasoning knowledge levels. The adopted classification levels were: concrete ( 0 to 8 right answers), transitory (9 to 14 right answers), formal (15 to 20 right answers), and postformal (21 to 24 right answers).

To compare the variables regarding their performance on the LCTSR and of individual characterization between the methods, Fisher' exact test was used for the qualitative variables and the Mann-Whitney test for the quantitative variables [Hollander et al. 2013]. Fisher's exact test verifies if there is a hypothesis association of two variables in a given sample, determining the exact observed frequency. The MannWhitney test is a non-parametric test employed in independent statistical samples.

Objectifying the verification of the students' score association with their respective ages and sexes, the Spearman correlation [Hollander et al. 2013] and the Mann Whitney test [Agresti and Kateri 2011] were used. 


\section{Results and Discussions}

This section presents the results and discussion of the sample descriptive analyses (Subsection 4.1), the comparative results between the traditional and the gamificationmediated methods (Subsection 4.3), and the discussions on the students' performance by gender (Subsection 4.4).

\subsection{Descriptive Analysis of the Sample}

For the data extraction procedure in the qualitative variable descriptive analyses, absolute and relative frequencies were used. In the quantitative variable description, position, central tendency, and dispersion measurements were used. Therefore, Table 1 quantitatively presents the descriptive variable analysis result.

Table 1. Variable descriptive analysis

\begin{tabular}{|c|c|c|c|}
\hline \multirow{2}{*}{ Method } & Variables & $\mathrm{N}$ & $\%$ \\
\cline { 2 - 4 } & Gamification & 21 & $47.73 \%$ \\
\hline \multirow{3}{*}{ Level } & Traditional & 23 & $52.27 \%$ \\
\hline \multirow{3}{*}{ Sex } & Concrete (C) & 35 & $81.40 \%$ \\
\cline { 2 - 4 } & Transitory Intermediary (ET) & 6 & $13.95 \%$ \\
\cline { 2 - 4 } & Transitory (LT) & 2 & $4.65 \%$ \\
\cline { 2 - 4 } & Female & 11 & $25.00 \%$ \\
\hline Right Answers & Male & 33 & $75.00 \%$ \\
\hline Score & Mean(S.D) & $22.28(15.32)$ \\
\hline
\end{tabular}

Through Table 1, we can notice that the most frequent method among the sample students was the traditional one-about $51 \%$-in comparison with the gamificationmediated algorithm teaching method. Evaluating the levels identified by the LCTSR, most of the students reached the concrete scientific logical knowledge level, with $81.4 \%$, followed by the transitory intermediary level, with $13.95 \%$.

Under the perspective of the students' right answer numbers in the LCTSR, we noticed that the right answer mean was of $22.28 \%$, with standard deviation (15.32). Regarding the students' performance, we noticed a mean of 3.16 , with standard deviation (2.05).

\subsection{Analyzing the Experience and Expectations of the Research Participants}

Regarding the knowledge of the concepts of algorithm and/or programming before starting the technical course, it was verified that about $39 \%$ of the subjects who used the traditional method had little knowledge about algorithm and/or programming ( $N=9)$ and approximately $56 \%$ reported that there was no knowledge $(\mathrm{N}=13)$. In relation to the gamification-mediated algorithm teaching method, about $14 \%$ of the subjects reported that they had little knowledge about algorithm and/or programming $(\mathrm{N}=3)$ (Figure 3).

It is observed that, through the analysis of the results, about $48 \%$ of the subjects who used the traditional method of programming teaching reported that learning by this method was below their expectations $(\mathrm{N}=11)$. In this sense, $39 \%$ of the subjects reported 


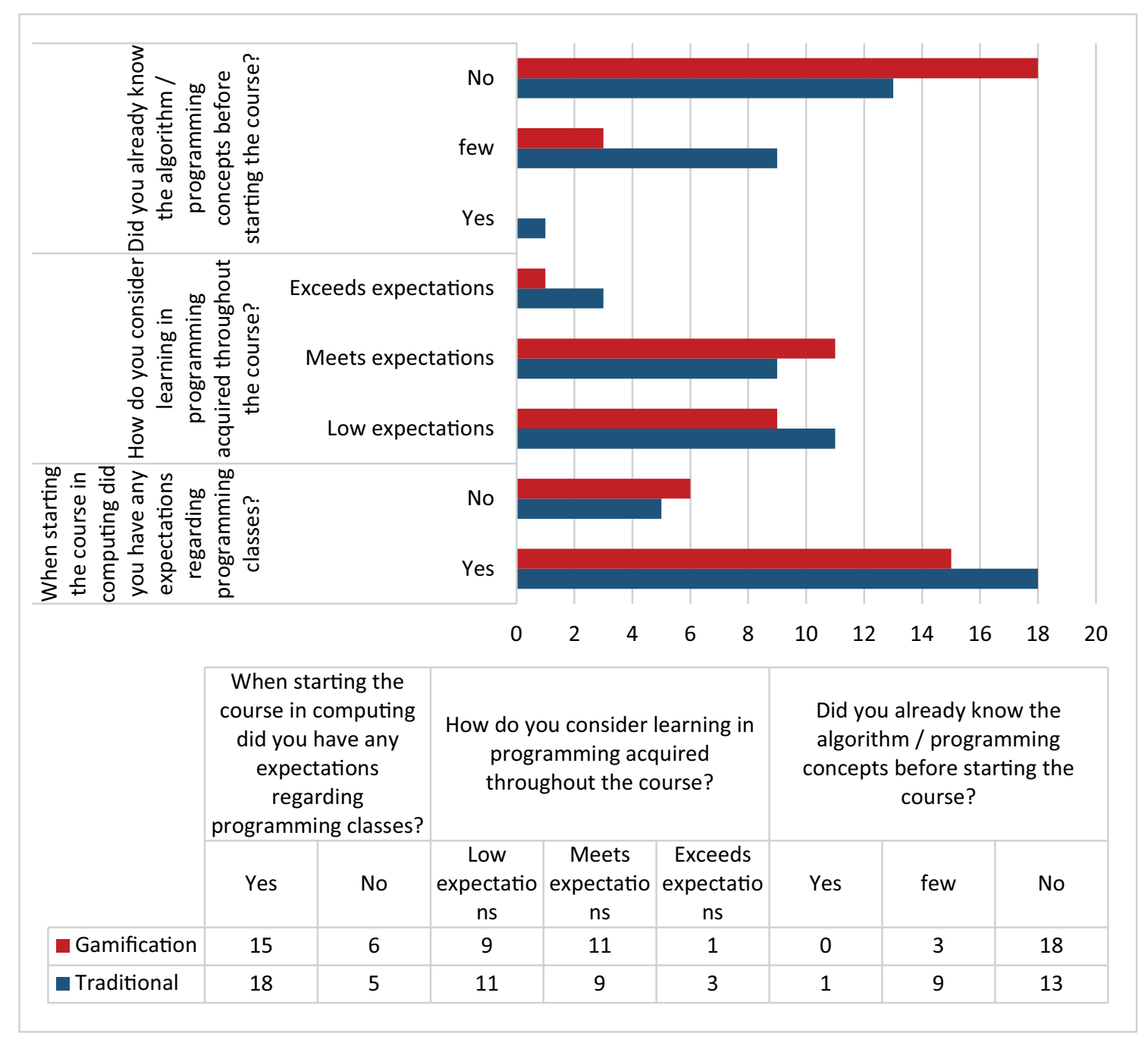

Figure 3. Experience and expectations of research participants

that learning through this method met their expectations $(\mathrm{N}=9)$ and approximately $13 \%$ reported that the traditional method exceeded their expectations $(\mathrm{N}=3)$.

Regarding the learning through the gamification-mediated algorithm teaching method, $43 \%$ of the participants reported that it was below their expectations $(\mathrm{N}=9)$. Approximately $53 \%$ of the participants reported that the method learning met their expectations $(\mathrm{N}=11)$ and $5 \%$ reported that the method exceeded their expectations $(\mathrm{N}=1)$.

Regarding the main difficulties encountered by the participants of this research in the algorithm and/or programming disciplines, approximately $65 \%$ of the subjects who used the Traditional Method reported that they had greater difficulties in relation to the teaching/didactic strategies of the process. About $21 \%$ of the subjects reported that the difficulties were caused by the lack of attention or effort of the student himself and $14 \%$ reported that the content was one of the biggest barriers faced.

In this sense, it can be noticed the inefficiency of traditional methods in comparison to the gamification-mediated algorithm teaching method. Thus, analyzing the method 
proposed by this research from the perspective of user satisfaction, approximately $43 \%$ of the participants indicated that the gamification-mediated algorithm teaching method obtained a satisfactory result. 50\% reported that the results using this method were regular and about $7 \%$ reported that the results obtained by this method were unsatisfactory.

Regarding the satisfaction of users in the traditional method, approximately $74 \%$ of the participants reported that the results obtained by this method were below their expectations, that is, regular or poor. Thus, about $93 \%$ of the subjects using this method indicated the need to use other methods in teaching algorithm and/or programming.

\subsection{Comparison between the Traditional and the Gamification-Mediated Methods}

To compare the two methods-traditional and gamification-mediated-we considered the right answer, score, and age variables. Consequently, Table 2 presents the comparison of such variables between both teaching methods.

\section{Table 2. Variable comparison between the traditional and gamification-mediated} methods

\begin{tabular}{|c|c|c|c|c|c|c|c|}
\hline \multicolumn{1}{|c|}{ Right Answers } \\
\hline Method & $\mathrm{N}$ & Mean & E.P. & $1 \mathrm{Q}$ & $2 \mathrm{Q}$ & $3 \mathrm{Q}$ & p-value \\
\hline Gamification & 21 & 28.10 & 4.06 & 17.00 & 25.00 & 33.00 & 0.018 \\
\hline Traditional & 22 & 16.73 & 1.83 & 8.00 & 17.00 & 25.00 & \\
\hline \multicolumn{10}{|c|}{ Score } \\
\hline Method & $\mathrm{N}$ & Mean & E.P. & $1 \mathrm{Q}$ & $2 \mathrm{Q}$ & $3 \mathrm{Q}$ & p-value \\
\hline Gamification & 21 & 4.00 & 0.51 & 3.00 & 4.00 & 5.00 & 0.012 \\
\hline Traditional & 23 & 2.39 & 0.29 & 1.50 & 3.00 & 3.00 & \\
\hline \multicolumn{10}{|c|}{ Age } \\
\hline Method & $\mathrm{N}$ & Mean & E.P. & $1 \mathrm{Q}$ & $2 \mathrm{Q}$ & $3 \mathrm{Q}$ & p-value \\
\hline Gamification & 21 & 22.71 & 0.12 & 16.00 & 17.00 & 17.00 & 0.000 \\
\hline Traditional & 23 & 21.13 & 0.11 & 15.00 & 15.00 & 15.00 & \\
\hline
\end{tabular}

Through Table 2, we can notice that there were significant differences between the traditional and the gamification-mediated teaching method ( $\mathrm{p}$-value $=0.018$ ), regarding the students' right answer numbers.

Therefore, the students that used the gamification-mediated algorithm teaching method presented a significantly higher mean in comparison with the students that used the traditional teaching method. Figure 4 presents the results of the correlations between the methods and the right answer, score, age, and gender variables.

We also notice that the gamification-mediated algorithm teaching method got a significantly greater mean score than the traditional teaching method ( $\mathrm{p}$-value $=0.012$ ). Regarding the students' age (Figure 4), the subjects that used the gamification-mediated algorithm teaching method got a significantly greater mean age in comparison with the ones that used the traditional teaching method $(\mathrm{p}$-value $=0.000)$.

Correlating the students' gender, between both methods, under the scientific logical knowledge and sex level, we identified significant differences. Therefore, Table 3 presents the results of the comparisons between the traditional and gamification-mediated teaching method.

We notice that there is a significant difference between both teaching methods ( $\mathrm{p}$-value $=0.034)$. Therefore, we noticed that the concrete scientific logical knowledge 

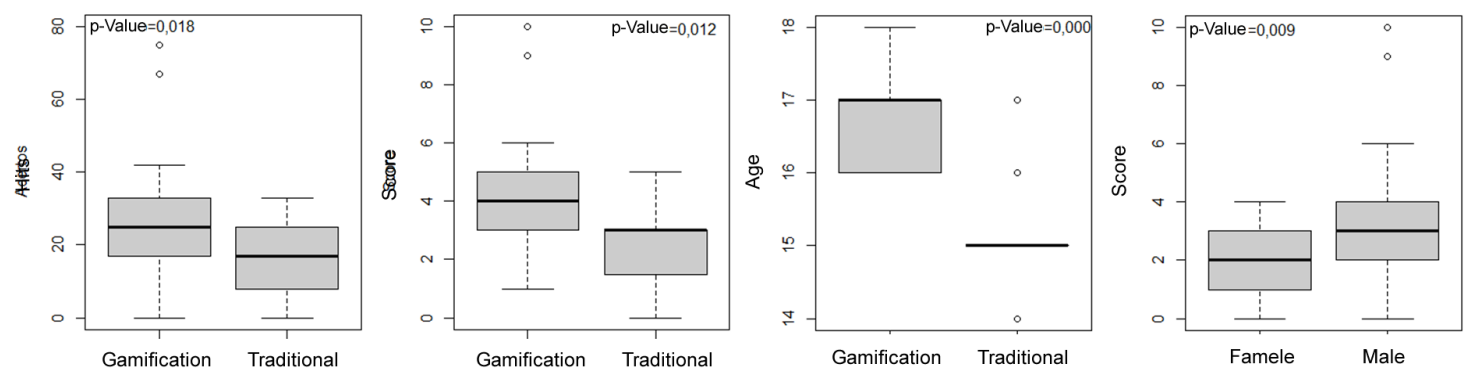

Figure 4. Right answer, score, and age variable comparison between the traditional and the gamification-mediated teaching methods

Table 3. Comparison of the level and sex variables between the traditional and gamification-mediated methods

\begin{tabular}{|c|c|c|c|c|c|c|}
\hline \multirow{3}{*}{\multicolumn{2}{|c|}{ Variables }} & \multicolumn{4}{|c|}{ Method } & \multirow{3}{*}{$\mathrm{p}$-value } \\
\hline & & \multicolumn{2}{|c|}{ Gamification } & \multicolumn{2}{|c|}{ Traditional } & \\
\hline & & $\mathrm{N}$ & $\%$ & $\mathrm{~N}$ & $\%$ & \\
\hline \multirow[t]{3}{*}{ Level } & $\mathrm{C}$ & 14 & $66.7 \%$ & 21 & $95.5 \%$ & \multirow[t]{3}{*}{0.034} \\
\hline & ET & 5 & $23.8 \%$ & 1 & $4.5 \%$ & \\
\hline & LT & 2 & $9.5 \%$ & 0 & $0.0 \%$ & \\
\hline \multirow[t]{2}{*}{ Sex } & Fem. & 4 & $19 \%$ & 7 & $30.4 \%$ & \multirow[t]{2}{*}{0.494} \\
\hline & Male & 17 & $81 \%$ & 16 & $69.6 \%$ & \\
\hline
\end{tabular}

level (C) presents a frequency of $95.5 \%$ in the traditional teaching method. However, the gamification-mediated algorithm teaching method presented $23.8 \%$ of transitory intermediary scientific logical knowledge levels (ET) and $9.5 \%$ of transitory scientific logical knowledge levels (LT). Therefore, the gamification-mediated algorithm teaching method was proven the most efficient, stimulating the students' intermediary and transitory reasoning.

\subsection{Performance between the Students (Gender)}

Through analyses, we identified significant differences between both methods regarding the students' gender ( $\mathrm{p}$-value $=0.009$ ). Table 4 presents the performance comparison of the tests between the students' genders.

Table 4. Performance comparison between the students' genders

\begin{tabular}{|c|c|c|c|c|c|c|c|c|}
\hline \multicolumn{2}{|c|}{ Variable } & N & Mean & E.P. & $1 \mathrm{Q}$ & $2 \mathrm{Q}$ & $3 \mathrm{Q}$ & $\mathrm{p}$-value \\
\hline \multirow{2}{*}{ Sex } & Fem. & 11 & 1.91 & 0.37 & 1 & 2 & 3 & 0.009 \\
\cline { 2 - 8 } & Male & 33 & 3.58 & 0.37 & 2 & 3 & 4 & \\
\hline
\end{tabular}

Through Table 4, we notice that there significant differences between the students' genders regarding the test. Therefore, we notice that the male students have a significantly greater mean than the female students (Figure 4).

Analyzing the occurrence of significant differences regarding the genders between both methods, we notice also that the male students got greater means than the female students in both teaching methods, traditional and gamification-mediated (Table 5). 
Table 5. Performance comparison between the students' genders

\begin{tabular}{|c|c|c|c|c|}
\hline \multicolumn{2}{|c|}{ Variable } & Method & Mean & p-value \\
\hline \multirow{3}{*}{ Sex } & Fem. & Gamification & 1.77 & 0.007 \\
\cline { 3 - 4 } & & Traditional & 1.61 & \\
\cline { 3 - 4 } & Male & Gamification & 3.2 & 0.005 \\
\cline { 3 - 4 } & & Traditional & 2.8 & \\
\hline
\end{tabular}

However, evaluating just the students' gain in each method, we notice that the gamification-mediated algorithm teaching method, in both genders, got significantly greater means in comparison with the students of the traditional teaching method. Therefore, we noticed that there was a positive and significant correlation $(r=0.34$ and $p$-value $=0.025$ ) between the variables: right answers, score, age, and sex.

Therefore, we notice through the analyses that gamification-mediated methods point to gains in the scientific logical reasoning regardless of the students' gender, stimulating greater intermediary and transitory levels.

\section{Conclusions}

The paper measured the cognitive development of computer higher education students under the perspective of scientific reasoning in algorithm teaching-learning processes between the traditional and the gamification-mediated teaching method.

Therefore, we used the LCTSR as our measuring tool to evaluate the cognitive capability between both student groups. The test verified through the issues of variable control, and hypothetical-deductive, proportional, and probabilistic reasoning, the indication of the scientific knowledge levels acquired by the students during the algorithm teaching-learning processes.

Through the analyses, we noticed the occurrence of significant differences between both methods. Therefore, we noticed that the students that used the gamificationmediated algorithm teaching method presented greater scientific logical knowledge levels in comparison with those that used the traditional teaching method.

Therefore, through the gamification-mediated algorithm teaching method, a significant number of students reached the transitory intermediary (ET) and transitory (LT) scientific knowledge levels, with greater rates of right answers in the LCTSR. We also noticed that both genders gave more right answers using the gamification-mediated algorithm teaching method.

Therefore, the gamification inclusion in algorithm teaching-learning processes proved itself efficient to stimulate the computer higher education students' cognitive development. Through these processes, the students developed scientific reasoning cognitive skills in the concrete, intermediary, transitory, formal and post-formal levels, contributing, therefore, as a significant improvement indicator in algorithm teaching-learning processes. That implies in the mental and intellectual development of who learns.

\section{References}

Acar, Ö. (2014). Scientific reasoning, conceptual knowledge, \& achievement differences between prospective science teachers having a consistent misconception and those hav- 
ing a scientific conception in an argumentation-based guided inquiry course. Learning and Individual Differences, 30:148-154.

Acar, Ö. and Patton, B. R. (2016). Examination of learning equity among prospective science teachers who are concrete, formal and postformal reasoners after an argumentation-based inquiry course. Australian Journal of Teacher Education, 41(2):n2.

Acar, Ö., Türkmen, L., and Bilgin, A. (2015). Examination of gender differences on cognitive and motivational factors that influence 8th graders' science achievement in turkey. Eurasia Journal of Mathematics, Science \& Technology Education, 11(5):1027-1040.

Agresti, A. and Kateri, M. (2011). Categorical data analysis. Springer.

Ding, L., Wei, X., and Liu, X. (2016). Variations in university students' scientific reasoning skills across majors, years, and types of institutions. Research in Science Education, 46(5):613-632.

Hollander, M., Wolfe, D. A., and Chicken, E. (2013). Nonparametric statistical methods. John Wiley \& Sons.

Jensen, J. L., Neeley, S., Hatch, J. B., and Piorczynski, T. (2017). Learning scientific reasoning skills may be key to retention in science, technology, engineering, and mathematics. Journal of College Student Retention: Research, Theory \& Practice, 19(2):126-144.

Khandelwal, S., Sripada, S. K., and Reddy, Y. R. (2017). Impact of gamification on code review process: An experimental study. In Proceedings of the 10th Innovations in Software Engineering Conference, pages 122-126. ACM.

Knutas, A., van Roy, R., Hynninen, T., Granato, M., Kasurinen, J., and Ikonen, J. (2017). Profile-based algorithm for personalized gamification in computer-supported collaborative learning environments. on CEUR in Proceedings of GHItaly.

Lawson, A. (2000). Classroom test of scientific reasoning: Multiple choice version. Author, Arizona State University. OpenURL.

Lawson, A. E. (2004). The nature and development of scientific reasoning: A synthetic view. International Journal of Science and Mathematics Education, 2(3):307.

Lopes, B., Duarte, W., Nogueira, T., Lopes, R., and Ferreira, D. (2016). Método de ensino de programação mediada por simulação: Um estudo de caso no curso técnico integrado em informática. In Brazilian Symposium on Computers in Education (Simpósio Brasileiro de Informática na Educação-SBIE), volume 27, page 340.

Opitz, A., Heene, M., and Fischer, F. (2017). Measuring scientific reasoning-a review of test instruments. Educational Research and Evaluation, 23(3-4):78-101.

Ouahbi, I., Kaddari, F., Darhmaoui, H., Elachqar, A., and Lahmine, S. (2015). Learning basic programming concepts by creating games with scratch programming environment. Procedia-Social and Behavioral Sciences, 191:1479-1482.

Pessoni, V. V., Federson, F. M., and Vincenzi, A. M. R. (2015). Learning difficulties in computing courses: Cognitive processes assessment methods research and application. 
In Proceedings of the XI Brazilian Symposium on Information Systems: Information Systems: A Computer Socio-Technical Perspective, volume 1, page 5.

Piaget, J., Inhelder, B., and Piaget, J. (2013). The growth of logical thinking from childhood to adolescence: An essay on the construction of formal operational structures, volume 84. Routledge.

Piraksa, C., Srisawasdi, N., and Koul, R. (2014). Effect of gender on student's scientific reasoning ability: A case study in thailand. Procedia-Social and Behavioral Sciences, 116:486-491.

Resnick, M., Maloney, J., Monroy-Hernández, A., Rusk, N., Eastmond, E., Brennan, K., Millner, A., Rosenbaum, E., Silver, J., Silverman, B., et al. (2009). Scratch: programming for all. Communications of the ACM, 52(11):60-67.

Seng, W. Y. and Yatim, M. H. M. (2014). Computer game as learning and teaching tool for object oriented programming in higher education institution. Procedia-Social and Behavioral Sciences, 123:215-224.

Topîrceanu, A. (2017). Gamified learning: A role-playing approach to increase student in-class motivation. Procedia Computer Science, 112:41-50.

Tsai, H.-C., Jou, M., Wang, J., and Huang, C.-C. (2016). An empirical study on the incorporation of app and progressive reasoning teaching materials for improving technical creativity amongst students in the subject of automatic control. Computers in Human Behavior. 